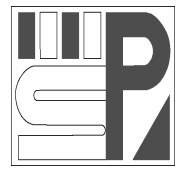

Science Press
Journal of Arid Land

2012, 4(2): 191-195

doi: 10.3724/SP.J.1227.2012.00191

jal.xjegi.com; www.chinasciencejournal.com

\title{
Winter habitat use of snow leopards in Tomur National Nature Reserve of Xinjiang, Northwest China
}

\author{
Feng $\mathrm{XU}^{1}$, Ming $\mathrm{MA}^{1 *}$, WeiKang YANG ${ }^{1}$, David BLANK ${ }^{1}$, YiQun $\mathrm{WU}^{2}$, Thomas MCCARTHY ${ }^{3}$, \\ Bariusha MUNKHTSOG ${ }^{4}$ \\ ${ }^{1}$ Key Laboratory of Biogeography and Bioresource in Arid Land, Xinjiang Institute of Ecology and Geography, Chinese Academy \\ of Sciences, Urumqi 830011, China; \\ ${ }^{2}$ Department of Environment and Life Sciences, Weinan Teachers University, Weinan 714000, China; \\ ${ }^{3}$ International Snow Leopard Trust, Seattle WA 98103, USA; \\ ${ }^{4}$ Institute of Biology, Mongolian Academy of Sciences, Ulaanbaatar 51, BZD, Mongolia
}

\begin{abstract}
Snow leopards are one of the least known large cats, the population of which has dramatically decreased. Their habitat loss was considered the main reason for the decline during the last decade, but their habitat preferences are still not well known. In this paper, we studied the winter habitat preferences of snow leopards in the Tomur National Nature Reserve (TNNR) in Northwest China during 2004-2005. We used sign surveys and transects to study the winter habitat selection of snow leopards. The results indicated that snow leopards showed a preference for habitat variabilities in slope aspect, vegetation cover, dominant topographical features, landform ruggedness and grazing status. We found that prey availability and dominant topographical features were the most important factors that determined the winter habitat selection of snow leopards. Our results supported the idea that the habitat preferences of snow leopards are a tradeoff between suitable habitat features and avoidance of potential human interactions.
\end{abstract}

Keywords: snow leopard; Panthera uncia; sign survey; habitat preferences; Tomur National Nature Reserve

Snow leopards (Panthera uncia) are one of the least known endangered species due to the remote and rugged habitat where they live in. They inhabit twelve countries, including Afghanistan, Bhutan, China, India, Kazakhstan, Kyrgyzstan, Mongolia, Nepal, Pakistan, Russia, Tajikistan, and Uzbekistan (Mallon, 1985; Fox, 1994; Jackson, 1996; Schaller, 1998; McCarthy, 2000). In China, the snow leopard has been found in the Tianshan Mountains, Kunlun Mountains, Altay Mountains, Himalayas, Hengduan Mountains and Qilian Mountains (Schaller et al., 1987; 1988; Yang, 1994; Wang, 1998; Ma et al., 2002; Xu et al., 2010).

Snow leopards were listed as 'endangered' in the International Union for Conservation of Nature and Natural Resources (IUCN) Red List and in Appendix I of the Convention on International Trade in Endangered Species (CITES) (Jackson, 1996; Schaller, 1998;
McCarthy, 2000). In spite of the fact that the snow leopard is a wide spread species, its population has steadily declined during the last several decades (Jackson, 1996; McCarthy, 2000; McCarthy and Chapron, 2003). Habitat destruction, fragmentation, over-grazing and illegal hunting have been proposed as the main reasons for the decline (Wang, 1998; McCarthy and Chapron, 2003). Thus, the habitat preference of snow leopards is a frequent research topic. Several studies about the habitat preferences of this endangered species were done in India, Nepal and Mongolia (Chundawat, 1991; Jackson, 1996; Oli, 1997; McCarthy et al., 2005). However, our knowledge on the habitat preferences of snow leopards in China, where an estimated $30 \%$ or more of snow leopards dwell (Schaller, 1998), remains unknown.

Received 2011-09-15; accepted 2011-12-26

*Corresponding author: Ming MA(E-mail: maming@ms.xjb.ac.cn) 
The purpose of our study was to investigate the habitat preferences of snow leopards in the Tomur National Nature Reserve (TNNR) in Northwest China. Our results can be used to develop a management strategy for snow leopards in China.

\section{Materials and methods}

\subsection{Study area}

Field work was conducted at the Tomur National Nature Reserve (TNNR), Xinjiang Uygur autonomous region in Northwest China $\left(80^{\circ} 07^{\prime}-80^{\circ} 52^{\prime} \mathrm{E}, 41^{\circ} 40^{\prime}-\right.$ $42^{\circ} 02^{\prime} \mathrm{N}$ ) during the winters of 2004 and 2005 . TNNR is located on the southern flank of the Tianshan Mountains and features about $3,000 \mathrm{~km}^{2}$ of rugged ridges and narrow valleys within altitudes ranging 2,000$7,000 \mathrm{~m}$. The climate is cold and the mean annual precipitation reaches 600-700 mm (Mountain Investigation Team of Chinese Academy of Sciences, 1985). The vegetation differs immensely between valley bottoms and mountain slopes. At valley bottoms near cliffs, there are a lot of tall shrubs $(50-80 \mathrm{~cm})$ such as Tamarix ramosissima, and the vegetation cover is relatively high $(>50 \%)$. On the mountain slopes, plants are typically short $(10-20 \mathrm{~cm})$ with dominant grass species such as Stipa capillata and Ceratoides lateens, having a relatively low vegetation cover $(<20 \%)$ (Mountain Investigation Team of Chinese Academy Sciences, 1985). Local fauna in direct contact with snow leopards was identified by direct observation of signs and by referring to literatures. They include wolves (Canis lupus), red foxes (Vulpes vulpes), ibexes (Capra sibirica), argali (Ovis ammon), snowcocks (Tetragallus altaicus), chukar partridge (Alectoris chukar) and small rodents (Mountain Investigation Team of Chinese Academy Sciences, 1985; Ma et al., 2006; Xu et al., 2010). The snow leopard population in the Tomur National Nature Reserve is estimated to be 40-80 individuals (Xu et al., 2011).

\subsection{Sampling method and variable design}

Direct observation of snow leopard is difficult due to the rough terrain of the study area, but signs like feces, scrapes, footprints left behind are effective indicators of their habitat distribution. In winter, the signs of snow leopards can be found easily and well detected in the field because of the presence of a snow cover, thus winter is the most suitable season for sign surveys (Jackson, 1996; McCarthy, 2000). The International Snow Leopard Trust (ISLT) established a detailed sampling technique for researching snow leopard sign density (Jackson and Hunter, 1996). McCarthy (2000) developed a modified sampling method and successfully applied it to study the habitat preferences of snow leopards in Mongolia. We adopted their method and randomly selected at least five sign transects for each study area, with a distance of at least $3,000 \mathrm{~m}$ between each two transects (McCarthy, 2000). The width of each transect was $10 \mathrm{~m}$, and the length fluctuated between 250-1,000 m. Snow leopard signs were carefully surveyed along the transects, and once a sign was found, the site was recorded as a sign site. For each sign site, the habitat attributes within a $20-\mathrm{m}$ radius were recorded, including elevation, slope aspect, vegetative cover, dominant topographic features, landform ruggedness and grazing status. For each transect, two random sites were selected and all habitat attributes were recorded. Random sites were selected with the help of a random number table. We randomly selected two numbers from 250 to 1,000, and used those numbers as the measure of random sites along the transect (McCarthy, 2000). Determination of habitat features followed methods used by Jackson and Hunter (1996), McCarthy (2000) and Ma et al. (2005). Among the above-mentioned attributes, landform ruggedness was the most subjective feature. To ensure consistency of the ruggedness class, it was estimated by the same person (McCarthy, 2000).

\subsection{Data analysis}

The Vanderloeg and Scavia selectivity index $\left(E_{i}\right)$ was used to identify snow leopard habitat preferences (Lechowicz, 1982; Wei et al., 2000). Selectivity index $\left(E_{i}\right)$ was calculated by the formula $E_{i}=\left(W_{i}-(1)\right.$ $n)) /\left(W_{i}+(1 / n)\right)$, where $W_{i}=\left(r_{i} / P_{i}\right) / \sum\left(r_{i} / P_{i}\right) . \quad W_{i}$ is the Vanderloeg and Scavia selectivity coefficient; $i$ is habitat feature class; $n$ is the total number of habitat feature classes defined; $P_{i}$ is the number of habitat features under the $i^{\text {th }}$ class in the studied area, and $r_{i}$ is the number of habitat features under the $i^{\text {th }}$ class used or not used by the snow leopard. The index value is scaled between -1 and +1 (Manly et al., 2002). If $E_{i}>0.1$, the snow leopard prefers this habitat. When 
$-0.1<E_{i}<0.1$, the snow leopard randomly uses this habitat feature, and if $E_{i}<-0.1$, the snow leopard avoids this habitat feature. A principal component analysis (PCA) was used for the multivariate analysis of sign site variables (Yang et al., 2003). For all analyses, we used the Software Package for Social Statistics (SPSS for Windows 16.0).

\section{Results}

\subsection{Snow leopard habitat preferences}

In total, we recorded 277 sign sites and 90 random sites during our field survey. Among the signs, 44\% is scrapes, 34\% footprints, 9\% feces, $7 \%$ claw rakes and $6 \%$ scents. We used only 271 sampled sign sites for analysis, because of the deficiency of data in the dominant topographic features. Snow leopards showed a preference for all habitat features except altitude (Table 1). Among the dominant topographic features, snow leopards preferred to use bases of cliffs and stream beds and avoided hillsides. They randomly used ridgelines, terraces/bluffs, and valley bottoms. For vegetation types, they preferred shrubs to barren areas and grasslands. With regards to ruggedness, snow leopards preferred to use moderately broken terrains and avoided rolling areas. They also preferred seasonal grazing areas to non-grazing ones. Southern and eastern slopes were more used than others.

\subsection{Factors dominating winter habitats}

The first three principal components met the criterion of eigenvalue $>1$ and altogether explained $74.5 \%$ of variance in sign sites (Table 2). The first principal axis ordered sites by vegetation cover, the second by dominant topographic feature, and the third by slope (Table 2). Combination of these results with snow leopard habitat preferences indicated that vegetation cover, topographic feature and slope aspect are the main factors which influenced winter habitat selection of snow leopards (Table 2). And snow leopards preferred the habitats of shrubs, bases of cliffs, and southern slopes (Table 1).

Table 1 Winter habitat preferences of snow leopard in TNNR, Xinjiang, China

\begin{tabular}{|c|c|c|c|c|c|c|}
\hline Ecological factors & Class $i$ & $P_{i}$ & $r_{i}$ & Selectivity coefficient $W_{i}$ & Selectivity index $E_{i}$ & Preference \\
\hline \multirow[t]{5}{*}{ Elevation $(\mathrm{m})$} & $2,000-2,500$ & 49.32 & 52.35 & 0.38 & 0.06 & Random \\
\hline & $2,500-3,000$ & 42.78 & 41.52 & 0.35 & 0.02 & Random \\
\hline & $3,000-4,000$ & 7.90 & 6.14 & 0.28 & -0.09 & Random \\
\hline & Cliff base & 16.07 & 19.19 & 0.21 & 0.12 & Prefer \\
\hline & Hillside & 7.48 & 3.32 & 0.08 & -0.36 & Avoid \\
\hline \multirow{5}{*}{$\begin{array}{c}\text { Dominant } \\
\text { topographic } \\
\text { feature }\end{array}$} & Ridge line & 21.33 & 19.56 & 0.16 & -0.01 & Random \\
\hline & Stream bed & 23.55 & 29.15 & 0.22 & 0.14 & Prefer \\
\hline & Terrace/bluff & 5.82 & 5.54 & 0.17 & 0.01 & Random \\
\hline & Valley bottom & 25.76 & 23.25 & 0.16 & -0.02 & Random \\
\hline & Barren & 6.27 & 2.89 & 0.16 & -0.23 & Avoid \\
\hline \multirow{4}{*}{$\begin{array}{l}\text { Vegetation } \\
\text { type }\end{array}$} & Forest & 8.72 & 7.22 & 0.28 & 0.06 & Random \\
\hline & Grass & 14.99 & 6.86 & 0.16 & -0.23 & Avoid \\
\hline & Shrub & 70.03 & 83.03 & 0.40 & 0.24 & Prefer \\
\hline & Rolling & 3.81 & 1.81 & 0.15 & -0.26 & Avoid \\
\hline \multirow[t]{3}{*}{ Ruggedness } & Moderately broken & 53.95 & 62.82 & 0.36 & 0.18 & Prefer \\
\hline & Slightly broken & 28.34 & 25.63 & 0.28 & 0.06 & Random \\
\hline & Highly broken & 13.90 & 9.75 & 0.22 & -0.07 & Random \\
\hline \multirow[t]{3}{*}{ Grazing status } & Non-grazing & 11.72 & 5.78 & 0.32 & -0.23 & Avoid \\
\hline & Seasonal & 88.28 & 94.22 & 0.68 & 0.16 & Prefer \\
\hline & $45^{\circ}-135^{\circ}$ & 35.15 & 44.40 & 0.35 & 0.17 & Prefer \\
\hline \multirow[t]{3}{*}{ Slope aspect } & $135^{\circ}-225^{\circ}$ & 30.52 & 35.02 & 0.32 & 0.12 & Prefer \\
\hline & $225^{\circ}-315^{\circ}$ & 19.62 & 14.08 & 0.20 & -0.11 & Avoid \\
\hline & $315^{\circ}-45^{\circ}$ & 14.71 & 6.50 & 0.12 & -0.34 & Avoid \\
\hline
\end{tabular}


Table 2 Interpretation of factors resulting from the principal analysis of habitat selection of snow leopards in TNNR, Xinjiang, China

\begin{tabular}{crrr}
\hline \multirow{2}{*}{ Ecological factors } & \multicolumn{3}{c}{ Principal components } \\
\cline { 2 - 4 } & \multicolumn{1}{c}{1} & \multicolumn{1}{c}{2} & \multicolumn{1}{c}{3} \\
\hline Elevation & -0.650 & 0.063 & 0.547 \\
Topography & 0.016 & 0.845 & 0.352 \\
Vegetation type & 0.858 & -0.184 & 0.126 \\
Grazing status & 0.681 & -0.294 & 0.285 \\
Ruggedness & -0.568 & -0.641 & -0.148 \\
Slope aspect & 0.049 & 0.437 & -0.733 \\
Eigenvalue & 1.948 & 1.441 & 1.079 \\
Percentage of total variance (\%) & 32.463 & 24.012 & 17.986 \\
Percentage of cumulative variance (\%) & 32.463 & 56.476 & 74.462 \\
\hline
\end{tabular}

\section{Discussion and conclusion}

Investigation and understanding of habitat preference is very important for wildlife conservation, especially for such endangered species like the snow leopard. After applying the Vanderloeg and Scavia selectivity index and PCA analysis, winter habitat preference of the snow leopard showed the following patterns.

First, in the TNNR, sheltered places, typically rugged terrains, bases of cliffs and stream beds were preferred by snow leopards, but rolling terrains and hillsides were avoided. These results are consistent with those described by other researchers. In India, Chundawat (1991) reported snow leopards showed a strong preference for steep, broken terrains, while smooth terrain was avoided. McCarthy (2000) reported that rolling and slightly broken habitats appear to be under represented in home ranges and markedly so in core leopard areas, while highly broken terrain appears over represented. These preferences can be explained by the needs of security. So, snow leopards preferred to use the areas where they can be well sheltered, like the rugged terrains and bases of cliffs, which also explains the preference for shrub over barren area and grassland.

Second, prey availability also affected the habitat choice of snow leopards. Ungulates are the main prey for snow leopards (Oli et al., 1993; Schaller, 1998; McCarthy, 2000; McCarthy et al., 2005) and ibex is the most common ungulate species in TNNR (Xu et al., 2006, 2007; Gao et al., 2011). Ibexes in TNNR showed a preference for eastern and southern slopes, and preferred shrubs over barren land, grassland and forest (Xu et al., 2007). Our results indicated that snow leopards showed the same habitat preferences as ibexes.

Third, human activities have also had a great impact on the habitat preferences of snow leopards. McCarthy (2000) reported that human activities affect the habitat preferences of snow leopards immensely, yet our results indicated the leopards preferred seasonal grazing areas over non-grazing areas in winter. This result seemed strange at first thought, but could be better understood after analysis. In the study area, there were large livestock populations, and most of the suitable habitats had been used by local shepherds even in the most remote areas. Only the most barren places were not used by livestock and they were regarded as non-grazing areas (Xu et al., 2006, 2007). Under these circumstances, most of the wild species, including snow leopards, preferred to live in seasonal grazing areas. Thus, the preference for seasonal grazing rather than non-grazing areas failed to show that human activities have a significant impact on snow leopards. Instead, it indicated the opposite that the remaining suitable habitats suitable for snow leopard survival are very limited in the study area.

Our data collected for snow leopards are still very limited because of their remote and rugged habitats. This study just produced a primary result, by which we tried to provide an insight into snow leopard habitat preferences. The topic itself, however, is complicated and requires further studies.

\section{Acknowledgments}

This research was supported by the Science Supporting Project of the National Ministry of Science and Technology (2008BA C39B04), the National Natural Science Foundation of China (30470262 and 30970340), the International Science and Technology Cooperation Program of China (2010DFA92720) and the Chinese Academy of Sciences Visiting Professorships for Senior International Scientists (2009Z2-5). We are grateful to the International Snow Leopard Trust (ISLT) and Xinjiang Conservation Fund (XCF) for financing this research. We thank the Xinjiang Forest Bureau and the TNNR Management Bureau for their support throughout this study. Thanks also go to Mr. Zumahon, Mr. Mulaming and Mr. Aizez for their help with the fieldwork. 


\section{References}

Chundawat R S. 1991. Habitat selection by snow leopard in Hemis National Park, India. International Pedigree Book of Snow Leopards, 6: 85-92.

Fox J. 1994. Snow leopard conservation in the wild-a comprehensive perspective on a low density fragmented population. In: Fox J. Proceedings of the Seventh International Snow Leopard Symposium. Seattle: International Snow Leopard Trust, 3-16.

Gao X Y, Xu W X, Yang W K, et al. 2011. Status and distribution of ungulates in Xinjiang, China. Journal of Arid Land, 3(1): 49-60.

Jackson R. 1996. Home range, movements and habitat use of snow leopard (Uncia unica) in Nepal. Ph.D. Dissertation. London: University of London, 1-233.

Jackson R, Hunter D O. 1996. Snow Leopard Information Management Survey and Conservation Handbook. Seattle: International Snow Leopard Trust, 1-120.

Lechowicz M J. 1982. The sampling characteristics of electivity indices. Oecologia, 52(1): 22-30.

Ma J Z, Zou H F, Cheng K. 2002. The distribution and status of snow leopard (Uncia uncia) in China. In: McCarthy T. Contributed Papers to the Snow Leopard Survival Strategy Summit. Seattle: International Snow Leopard Trust, 209-212.

Ma M, Munkhtsog B, Xu F, et al. 2005. Markings as indicator of snow leopard in field survey Xinjiang. Chinese Journal of Zoology, 40(4): 34-39.

Ma M, Xu F, Chundawat R S, et al. 2006. Camera trapping of snow leopards for the photo capture rate and population size in the Muzat Valley of Tianshan Mountains. Acta Zoologica Sinica, 52(4): 788-793.

Mallon D. 1985. The mammals of the Mongolian People's Republic. Mammal Review, 15: 71-102.

Manly B F, McDonald L, Thomas D L, et al. 2002. Resource Selection by Animals: Statistical Design and Analysis for Field Studies. Boston: Kluwer Press, 1-233.

McCarthy T. 2000. Ecology and conservation of snow leopards, gobi brown bears and wild bactrian camels in Mongolia. Ph.D. Dissertation. Amherst: University of Massachusetts, 3-330.

McCarthy T, Chapron C. 2003. Snow Leopard Survival Strategy. Seattle: International Snow Leopard Trust and Snow Leopard Network, 209-212.

McCarthy T, Fuller T, Munkhtsog B. 2005. Movements and activities of snow leopard in southwestern Mongolia. Biological Conservation, 124: 527-537.

Mountain Investigation Team of Chinese Academy of Sciences. 1985. The Biology Resources of Tomur Area of Tianshan Mountains. Urumqi: Xinjiang People Press, 1-353.

Oli M K, Taylor I R, Rogers D M E. 1993. Diet of the snow leopard (Panthera uncia) in the Annapurna Conservation Area, Nepal. Journal of Zoology, 231(3): 365-370.

Oli M K. 1997. Winter home range of snow leopard in Nepal. Mammalia, 61: 335-360.

Schaller G, Li H, Talipu, et al. 1987. Status of large mammals in the Taxkorgan Reserve, Xinjiang, China. Biological Conservation, 42(1): 53-71.

Schaller G, Li H, Talipu, et al. 1988. The snow leopard in Xinjiang, China. Oryx, 22(4): 197-204.

Schaller G. 1998. Wildlife of the Tibetan Steppe. Chicago: University of Chicago Press, 1-373.

Wang S. 1998. China Red Data Book of Endangered Animals. Beijing: Science Press, 132-135.

Wei F W, Feng Z J, Wang Z W, et al. 2000. Habitat use and separation between the giant panda and the red panda. Journal of Mammalogy, 81(2): 448-455.

$\mathrm{Xu} \mathrm{F}$, Ma M, Wu Y Q. 2006. Winter daily activity rhythm and time budget of ibex (Capra ibex) in Tomur Protected Area, Xinjiang. Chinese Journal of Zoology, 41(6): 139-141.

Xu F, Ma M, Wu Y Q. 2007. Population density and habitat utilization of ibex (Capra ibex) in Tomur National Nature Reserve, Xinjiang, China. Zoological Research, 28(1): 53-55.

$\mathrm{Xu}$ F, Ma M, Wu Y Q. 2010. Recovery of snow leopard Uncia uncia in Tomur National Nature Reserve of Xinjiang, Northwest China. Pakistan Journal of Zoology, 42(6): 825-827.

$\mathrm{Xu}$ F, Ma M, Wu Y Q. 2011. Population density of snow leopards (Panthera uncia) in Tomur National Nature Reserve of Xinjiang, China. Acta Theriologica Sinica, 31(2): 205-210.

Yang Q S. 1994. Further study on the geographical distribution and conservation of snow leopard in Qinghai. In: Fox J. Proceedings of the Seventh International Snow Leopard Symposium. Seattle: International Snow Leopard Trust, 72-77.

Yang W K, Qiao J F, Combreau O, et al. 2003. Breeding habitat selection by the Houbara Bustard Chlamydotis [undulata] macqueenii in Mori, Xinjiang, China. Zoological Studies, 42(3): 471-475. 